PRELIMINARY REPORT

\title{
Transfer of Opiorphin Through a Blood-Brain Barrier Culture Model
}

\author{
Alexandra Bocsik, ${ }^{\mathrm{a}}$ Zsuzsanna Darula, ${ }^{\mathrm{b}}$ Géza Tóth, ${ }^{\mathrm{b}}$ Mária A. Deli, ${ }^{\mathrm{a}}$ and Mária Wollemann ${ }^{\mathrm{b}}$
}

anstitute of Biophysics, ${ }^{\mathrm{b}}$ Biochemistry, Biologial Research Centre, Hungarian Academy of Sciences, Szeged, Hungary

Received for publication February 24, 2015; accepted June 23, 2015 (ARCMED-D-15-00127).

\begin{abstract}
Opioid peptides are potent analgesics with therapeutic potential in the treatment of acute and chronic pain. Their efficacy is limited by peptidases (enkephalinases). Opiorphin pentapeptide (QRFSR) is the first characterized human endogenous inhibitor of enkephalinases. The peptide is able to increase the binding and affinity of endogenous opiates to mu opioid receptors; thus, the mechanism of opiorphin may provide a new therapeutic approach in pain management. The analgesic effect of opiorphin was proven in several earlier published in vitro and in vivo studies. Our aim was to test the transfer of opiorphin through a blood-brain barrier model for the first time. The flux of opiorphin was tested on a blood-brain barrier culture model consisting of rat brain endothelial, glial and pericyte cells. Brain endothelial cells in this triple co-culture model form tight monolayers characterized by transendothelial electrical resistance measurement. Relative quantity of the peptide was estimated by mass spectrometry. The transfer of opiorphin through the bloodbrain barrier model was estimated to be $\sim 3 \%$, whereas the permeability coefficient was $0.53 \pm 1.36 \times 10^{-6} \mathrm{~cm} / \mathrm{s}(n=4)$. We also observed rapid conversion of N-terminal glutamine into pyroglutamic acid during the transfer experiments. Our results indicate that opiorphin crosses cultured brain endothelial cells in the absence of serum factors in a significant amount. This is in agreement with previous in vivo data showing potentiation of enkephalin-mediated antinociception. We suggest that opiorphin may have a potential as a centrally acting novel drug to treat pain. (C) 2015 IMSS. Published by Elsevier Inc.
\end{abstract}

Key Words: Opiorphin, Peptidase inhibitor, Blood-brain barrier, Brain endothelial cell, Permeability, LC-MS.

\section{Introduction}

Opioid analgesics are still one of the most effective drugs against pain; however, their clinical usefulness is limited by several side effects including physical dependence, respiratory depression, gastrointestinal effects and tolerance (1). New opioid peptides could have therapeutic potential for central nervous system (CNS) diseases, but they have a short half-life and low metabolic stability $(2,3)$. Opiorphin (QRFSR) is an endogenous peptide that inhibits Zn-dependent metallo-ecto-peptidases, neutral endopeptidase (NEP EC3.4.21.11) and aminopeptidase (AP-N EC3.4.11.2) (4). These enzymes metabolize opioid peptides such as enkephalins and their derivatives in vivo

Address reprint requests to: Mária A. Deli, MD, PhD, DSc, Institute of Biophysics, Biological Research Centre, Hungarian Academy of Sciences, Temesvari krt. 62, H-6726 Szeged, Hungary; Phone: (+36) (62) 599602; FAX: (+36) (62) 433133; E-mail: deli.maria@brc.mta.hu and in vitro (5). Opiorphin as an enkephalinase inhibitor exerts analgesic and antidepressive effects by the protection of endogenous enkephalins released after pain stimuli $(6,7)$. Opiorphin is the only natural enkephalinaseinhibitor characterized in humans and has similar painsuppressive potency to morphine but without adverse effects $(4,6)$. The efficacy of opiorphin has been verified by in vitro methods and its analgesic activity was also shown in different in vivo pain studies $(4,6,8)$. According to our previous in vitro maximal binding and affinity measurements, opiorphin is able to increase the binding and affinity of endogenous opiates to opioid receptors (9).

In this study we were interested in the opiorphin transfer across the BBB. Opioid peptides have restricted penetration to the CNS across the BBB $(10,11)$. The transfer of opioid peptides through the BBB was studied previously with isotopically labeled peptides showing a penetration index $<0.01 \%$ (12-14). Specific features of the BBB, mainly interendothelial tight junctions and efflux transporters (15), as
65

66

67

68

69

70

71

72

73

74

75

76

77

78

79

80

81

82

83

84

85

86

87

88

89

90

91

92

93

94

95

96

97

98

99

100

101 
well as peptidase activity in blood, brain microvessels and brain tissue may be responsible for limiting the transfer of these potential biotherapeutics from the blood to brain.

The aim of the study was to test the transfer of unlabeled opiorphin across a well-characterized culture model of the BBB. Mass spectrometry was used to detect the passage of the peptide across the $\mathrm{BBB}$ in vitro.

\section{Materials and Methods}

\section{Materials}

All reagents used in the study were purchased from SigmaHungary Ltd. (Budapest, Hungary) unless otherwise indicated. Wistar rats were obtained from the animal facility of the BRC. All animals were treated in strict accordance with the NIH Guide for Care and Use of Laboratory Animals (NIH Publications No. 80-23) and as approved by the local authority, Csongrád County Animal Health and Food Control Station (Permit number: XVI./834/2012).

\section{Peptide Synthesis}

Opiorphin was synthesized manually using Fmoc (fluorenylmethyloxycarbonyl) solid phase synthesis on $\mathrm{N}^{\alpha}$ Fmoc-Arg(Pmc)-Wang resin. $\mathrm{N}^{\alpha}$-Fmoc-protected amino acids were used. The side chain protecting groups used to build the peptide sequence were the following: trityl (Trt) for Gln, tert-butyl (t-Bu) for Ser and 2,2,5,7,8pentamethylchroman (Pmc) for Arg. The couplings were performed by 1-hydroxybenzotriazole (HOBt) and $\mathrm{N}, \mathrm{N}^{\prime}$ diisopropylcarbodiimide (DIC). The coupling efficiencies were monitored by the Kaiser test. The Fmoc groups were removed by a solution of $20 \%$ piperidine in dimethylformamide. After assembly of the peptide sequence, a cocktail of TFA/TIS/ $\mathrm{H}_{2} \mathrm{O}$ (trifluoroacetic acid/triisopropylsilane/water, 95: $2.5: 2.5$ ) was used to remove the side chain protecting groups and to cleave the peptide from the resin. The resin was filtered and the filtrate was cooled at $-20^{\circ} \mathrm{C}$. After precipitating with diethyl ether, the peptide was redissolved in water and lyophilized. The crude peptide was purified using a semipreparative RP-HPLC column (Altima HP of the final peptide was determined by analytical RP-HPLC (Altima HP C ${ }_{18} 0.46 \mathrm{~cm} \times 25 \mathrm{~cm}, 5 \mu \mathrm{m}$ particle size) column, retention time: $6.5 \mathrm{~min}$. ESI-MS analysis confirmed the molecular mass of the peptide $\left(\left[\mathrm{M}+\mathrm{H}^{+}\right]_{\text {found }}\right.$ : 693.5 ; $\left(\left[\mathrm{M}+\mathrm{H}^{+}\right]_{\text {theoretical }}: 693.4 \mathrm{Da}\right)$.

\section{Blood-Brain Barrier Model}

Primary brain endothelial cells, astrocytes and pericytes were isolated from 1-month-old Wistar rats. Cell isolation and the preparation of the co-culture BBB model was performed as previously described (16). Brain endothelial cells and pericytes were seeded on the opposite surfaces of collagen IV and fibronectin coated Costar Transwell polycarbonate inserts ( $12 \mathrm{~mm}$ diameter, $0.4 \mu \mathrm{m}$ pore size; Corning, Corning, NY) and kept in co-culture with glial cells to reach good barrier properties for the permeability measurements (Figure 1A). The tightness of the model was checked by transendothelial electrical resistance (TEER) measurement using an EVOM resistance meter and STX-2 electrodes (World Precision Instruments, USA). TEER of coated, cell-free filters was subtracted from measured TEER values of the BBB model. TEER of rat brain endothelial cell layers was $593 \pm 47 \Omega \mathrm{cm}^{2}$ (mean $\pm \mathrm{SD}$; $n=12$ ) in agreement with our previous data (17).

\section{Bidirectional Permeability Assay}

To measure the transfer of opiorphin across the BBB model, cell culture inserts were transferred to 12-well plates containing $1.5 \mathrm{~mL}$ Ringer-Hepes solution $(136 \mathrm{mM} \mathrm{NaCl}$, $0.9 \mathrm{mM} \mathrm{CaCl}, 0.5 \mathrm{mM} \mathrm{MgCl}, 2.7 \mathrm{mM} \mathrm{KCl}, 1.5 \mathrm{mM}$ $\mathrm{KH}_{2} \mathrm{PO}_{4}, 10 \mathrm{mM} \mathrm{NaH} \mathrm{PO}_{4}, 25 \mathrm{mM}$ glucose and $10 \mathrm{mM}$ Hepes, pH 7.4) in the lower or acceptor compartments. The peptide was dissolved in distilled water to yield a $10-\mathrm{mM}$ solution, which was further diluted in RingerHepes buffer. In the upper or donor chambers, culture medium was replaced by $0.5 \mathrm{~mL}$ Ringer Hepes containing opiorphin at $10 \mu \mathrm{M}$ concentration or permeability markers fluorescein $(10 \mu \mathrm{g} / \mathrm{mL}$; molecular weight: $376 \mathrm{Da})$ or $\mathrm{C}_{18}, 1 \mathrm{~cm} \times 25 \mathrm{~cm}, 5 \mu \mathrm{m}$ particle size). The homogeneity

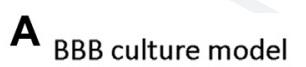

B Permeability assay

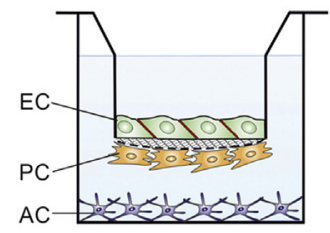

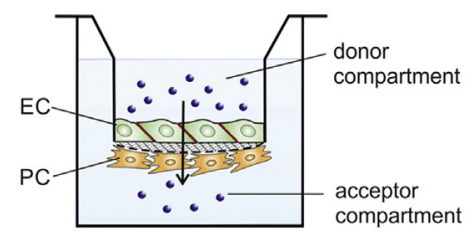

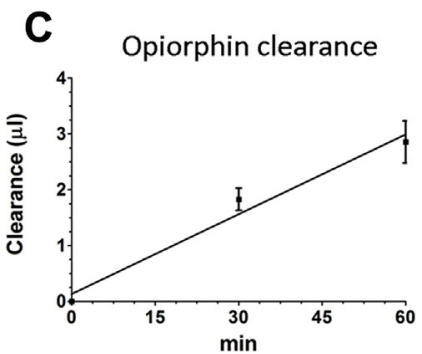

223

Figure 1. Culture model of the blood-brain barrier (A). The model is a co-culture of three cells types, primary rat brain endothelial cells (EC), rat pericytes (PC) and rat astrocytes (AC). In the permeability assay (B) culture inserts with EC and PC cells are used. Blue circles represent opiorphin, our test molecule. The direction of the transfer from the donor to the acceptor compartment is indicated by an arrow. Clearance of opiorphin across the culture model (C) 
bovine serum albumin (1\%, molecular weight: $65 \mathrm{kDa})$ bound to Evans blue (165 $\mu \mathrm{g} / \mathrm{mL})$ (Figure 1B). To measure peptide flux from the upper to lower compartment (blood to brain direction) the inserts were transferred at 30 and $60 \mathrm{~min}$ to new wells containing Ringer-Hepes solution. Opiorphin in samples from the donor and acceptor compartments $(n=4)$ were detected by mass spectrometry. Evans blue-albumin content of samples was measured at $584 \mathrm{~nm}$ excitation and $680 \mathrm{~nm}$ emission wavelengths (Fluostar Optima, BMG Labtechnologies, Germany). Fluorescein concentrations were determined by the same instrument using $485 \mathrm{~nm}$ excitation and $520 \mathrm{~nm}$ emission wavelengths. Clearance and the apparent permeability coefficient $\left(\mathrm{P}_{\mathrm{app}}\right)$ were calculated as described earlier (16) by the following equations:

$$
\text { Cleared volume }(\mu \mathrm{l})=\frac{C_{A} \times V_{A}}{C_{D}}
$$

where $\mathrm{C}$ is concentration of the peptide in the acceptor or donor compartments and $\mathrm{V}$ is the volume of the acceptor compartment $(1.5 \mathrm{ml})$.

$$
P_{\text {app }}(\mathrm{cm} / \mathrm{s})=\frac{\Delta[C]_{A} \times V_{A}}{A \times[C]_{D} \times \Delta t}
$$

where $\Delta[C]_{\mathrm{A}}$ is the concentration difference of the peptide in the acceptor compartments after $1 \mathrm{~h}$ and $\mathrm{C}_{\mathrm{D}}$ is the concentration in the donor compartments at $0 \mathrm{~h}$, and $\mathrm{V}_{\mathrm{A}}$ is the volume of the acceptor compartment $(1.5 \mathrm{~mL})$, and $\mathrm{A}$ is the surface area available for permeability $\left(1.1 \mathrm{~cm}^{2}\right)$. The quantity of opiorphin transfer was calculated from areas under curve from the chromatograms representing the intact opiorphin peptide.

\section{Mass Spectrometry}

LC-MS experiments were performed on a nanoAcquity UPLC (Waters) on-line coupled to an Orbitrap-Elite (Thermo Scientific) hybrid tandem mass spectrometer operated in the positive ion mode. Five $\mu l$ of the samples containing the peptide was injected onto a trapping column (Waters Symmetry C18; $180 \mu \mathrm{m} \times 20 \mathrm{~mm}, 5 \mu \mathrm{m}$ particle size) and after washing with $1 \%$ solvent B for 5 min was transferred onto the separating column (Dionex Acclaim PepMap; $75 \mu \mathrm{m} \times 25 \mathrm{~cm}, 2 \mu \mathrm{m}$ particle size, $100 \AA$ pore size) developing a linear gradient of $1-35 \%$ solvent $\mathrm{B}$ in $10 \mathrm{~min}$ using a flow rate of $200 \mathrm{nl} / \mathrm{min}$ (solvent A: $0.1 \%$ for$\mathrm{mic}$ acid/water; solvent B: $0.1 \%$ formic acid/acetonitrile). For MS experiments, mass range of m/z: 200-600 was monitored at resolution of 60000 using internal calibration to the background polysiloxane ion (m/z: 445.120024). Relative quantity of opiorphin was estimated using the extracted ion chromatogram (XIC) of m/z: $347.1932( \pm 5$ ppm) peak intensity corresponding to the doubly charged opiorphin peptide cation.

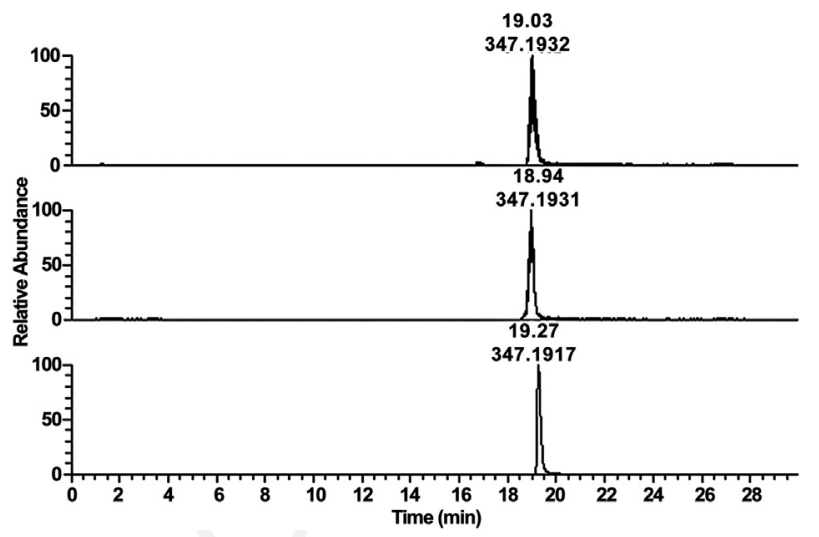

Figure 2. Extracted ion chromatograms of m/z: $347.1932 \pm 5$ ppm corresponding to the doubly charged peptide ion of opiorphin. Upper panel: sample from the receiver compartment ("brain side") after 30 min incubation, middle panel: sample from the receiver compartment after 60 min incubation, bottom panel: sample from the donor compartment ("blood side") after $60 \mathrm{~min}$ incubation. Peak labels denote retention time and $\mathrm{m} / \mathrm{z}$ value.

\section{Results}

MS/MS characterization of the synthetic opiorphin peptide was performed using both collision-induced dissociation and higher energy collisional activation. The observed $\mathrm{m} /$ $\mathrm{z}$ value of the protonated peptide ions and fragmentation pattern were in good agreement with those expected for the QRFSR sequence. Signal intensities in the receiver compartment samples were $1-2 \times 10^{6}$ as opposed to 1.5 $\times 10^{8}$ in the donor compartment samples (Figure 2).

The relative quantity of opiorphin that penetrated through the BBB model was calculated to be $2.91 \pm 1.13 \%$ based on the area under curve of the doubly charged opiorphin peptide ion $\mathrm{m} / \mathrm{z} 347.1932$. As a comparison, $0.41 \pm 0.03 \%$ of fluorescein and $0.03 \pm 0.01 \%$ of albumin crossed the brain endothelial cell layers in parallel inserts from the same cell isolation under identical assay conditions.

The clearance of opiorphin is shown in Figure 1C. $\mathrm{P}_{\mathrm{app}}$ of opiorphin was $0.53 \pm 1.36 \times 10^{-6} \mathrm{~cm} / \mathrm{s}(n=4)$. In parallel inserts from the same cell isolation under identical assay conditions the $\mathrm{P}_{\text {app }}$ of fluorescein was $1.03 \pm 0.09$ $\times 10^{-6} \mathrm{~cm} / \mathrm{s}(n=4)$ and that of albumin $0.07 \pm 0.04 \times$ $10^{-6} \mathrm{~cm} / \mathrm{s}(n=4)$.

We also observed rapid conversion of N-terminal glutamine into pyroglutamic acid both in $0.1 \%$ formic acid and in Ringer-Hepes buffer used for BBB penetration experiments. We monitored the pyroglutamic acid-containing peptide using its calculated molecular mass [monoisotopic MW: 675.3453 yielding a doubly charged protonated peptide ion $\mathrm{m} / \mathrm{z}: 338.6799(\mathrm{z}=2)]$.

\section{Discussion}

We measured the transfer of opiorphin across a BBB culture model for the first time. The resistance data and $\mathrm{P}_{\mathrm{app}}$
310

311

312

313

314

315

316

317

318

319

320

321

322

323

324

325

326

327

328

329

330

331

332

333

334

335

336

337

338

339

340

341

342

343

344 
values for passive hydrophilic permeability markers fluorescein and albumin were in accordance with our previous data and indicated a tight barrier $(16,17)$. Instead of radiolabeling we used the native form of the peptide and a sensitive method, LC-MS, to detect opiorphin. A mass spectrometry method was already applied for the quantification of opiorphin in human saliva (18). Our data indicate that opiorphin crosses the BBB in vitro in the absence of plasma factors at a slow rate, which is lower than that of the paracellular marker fluorescein but higher than that of the passive transcellular marker albumin. At the same time the extent of penetration was significant, $\sim 3 \%$ in contrast to the low amount of the paracellular markers. As a comparison, numerous endogenous peptides or regulatory proteins have $<0.1 \% / g$ uptake in brain and are still effective in the CNS after peripheral administration $(12-14,19)$. Among the opiates, the centrally active morphine has an uptake of only $<0.02 \% / \mathrm{g}$ brain $(20)$.

The amount of opiorphin transferred across the BBB culture model indicates that a specific transport mechanism, a peptide transport system or receptor-mediated transcytosis, may be involved in its transfer. Six transport systems (PTS1-6) have been identified for peptides at the BBB, which transport enkephalins, arginine vasopressin, or pituitary adenylate cyclase-activating polypeptides, among others (11). The peptide/histidine transporter 2 (PHT2, SLC15a3) was described at the BBB carrying di- and tripeptides, whereas larger peptides or proteins like insulin or transferrin cross the BBB by receptor-mediated transcytosis (15). To reveal if carriers or transporters participate in opiorphin transfer, further experiments are needed.

We observed the conversion of $\mathrm{N}$-terminal glutamine into pyroglutamic acid in the peptide samples. Peptide Nterminal glutamines are prone to cyclization yielding pyroglutamic acid. This reaction can be catalyzed enzymatically by cyclization of L-glutamine and L-glutaminyl peptides (21), but the reaction also happens spontaneously, especially at acidic $\mathrm{pH}$ values. The presence of glutaminyl cyclase is described in brain but not known at the level of brain capillaries and there are no data on how pyroglutamate formation modifies the transport of peptides across the BBB. The tripetide thyrotropin-releasing hormone contains a pyroglutamate and has a slow, but in vivo measurable penetration across the BBB (22).

The relative quantity of opiorphin penetration through the BBB culture model is obviously more elevated than values obtained with iv-administered labeled opioid peptides (14). A possible explanation for this difference is that in our culture system no serum factors were present during the experiments, which is a limitation of the model. Peptidases are active in blood and rapidly cleave the native opiorphin peptide, which has a metabolic half-life of 6 min in human plasma; therefore, enzyme activity limits the transfer of opiorphin to the CNS in vivo $(4,23,24)$. In vivo data suggest that even in the presence of serum peptidases opiorphin can cross the BBB in sufficient amounts to raise the concentration of endogenous opioid ligands by inhibiting enkephalinases; thus, it can be appropriate for producing central effects.

In conclusion, our results indicate that opiorphin crosses cultured brain endothelial cells. These data are in agreement with observations that opiorphin potentiates enkephalinmediated antinociception and exerts antidepressant-like effects. We suggest that opiorphin may have a potential for further development as a centrally acting novel drug for the treatment of pain or depression.

\section{Acknowledgments}

The study was supported by TAMOP-4.2.2A-11/1KONV-20120024 and OTKA 108518 grants.

\section{References}

1. Meert TF, Vermeirsch HA. A preclinical comparison between different opioids: antinociceptive versus adverse effects. Pharmacol Biochem Behav 2005;80:309-326.

2. Janecka A, Staniszewska R, Gach K, et al. Enzymatic degradation of endomorphins. Peptides 2008;29:2066-2073.

3. Tömböly C, Péter A, Tóth G. In vitro quantitative study of the degradation of endomorphins. Peptides 2002;23:1573-1580.

4. Wisner A, Dufour E, Messaoudi M, et al. Human opiorphin, a natural antinociceptive modulator of opioid-dependent pathways. Proc Natl Acad Sci U S A 2006;103:17979-17984.

5. Roques BP, Fournié-Zaluski MC, Wurm M. Inhibiting the breakdown of endogenous opioids and cannabinoids to alleviate pain. Nat Rev Drug Discov 2012;11:292-310.

6. Rougeot C, Robert F, Menz L, et al. Systematically active human opiorphin is a potent yet non-addictive analgesic without drug tolerance effects. J Physiol Pharmacol 2010;61:483-490.

7. Javelot H, Messaoudi M, Garnier S, et al. Human opiorphin is a naturally occurring antidepressant acting selectively on enkephalindependent delta-opioid pathways. J Physiol Pharmacol 2010;61: $355-362$.

8. Tian XZ, Chen J, Xiong W, et al. Effects and underlying mechanisms of human opiorphin on colonic motility and nociception in mice. Peptides 2009;30:1348-1354.

9. Tóth F, Tóth G, Benyhe S, et al. Opiorphin highly improves the specific binding and affinity of MERF and MEGY to rat brain opioid receptors. Regul Pept 2012;178:71-75.

10. Banks WA. Delivery of peptides to the brain: emphasis on therapeutic development. Biopolymers 2008;90:589-594.

11. Banks WA. Peptides and the blood-brain barrier. Peptides; 2015; http://dx.doi.org/10.1016/j.peptides.2015.03.010.

12. Zlokovic BV, Mackic JB, Djuricic B, et al. Kinetic analysis of leucineenkephalin cellular uptake at the luminal side of the blood-brain barrier of an in situ perfused guinea pig brain. J Neurochem 1989;53: 1333-1340.

13. Weber SJ, Abbruscato TJ, Brownson EA, et al. Assesment of an in vitro blood-brain barrier model using several $\left[\mathrm{Met}^{5}\right]$ enkephalin opioid analogs. J Pharmacol Exp Ther 1993;266:1649-1655.

14. Banks WA, Kastin AJ. Passage of peptides across the blood-brain barrier. Pathophysiological perspectives. Life Sci 1996;59:1923-1943.

15. Campos-Bedolla P, Walter FR, Veszelka S, et al. Role of the bloodbrain barrier in the nutrition of the central nervous system. Arch Med Res 2014;45:610-638. 
16. Nakagawa S, Deli MA, Kawaguchi H, et al. A new blood-brain barrier model using primary rat brain endothelial cells, pericytes and astrocytes. Neurochem Int 2009;54:253-263.

17. Hülper P, Veszelka S, Walter FR, et al. Acute effects of short-chain alkylglycerols on blood-brain barrier properties of cultured brain endothelial cells. Br J Pharmacol 2013;169:1561-1573.

18. Brkljacic L, Sabalic M, Salaric I, et al. Development and validation of a liquid chromatography-tandem mass spectrometry method for the quantification of opiorphin in human saliva. $\mathrm{J}$ Chromatogr B Analyt Technol Biomed Life Sci 2011;879: 3920-3926.

19. Banks WA. The CNS as a target for peptides and peptide-based drugs. Expert Opin Drug Deliv 2006;3:707-712.
20. Advokat C, Gulati A. Spinal transection reduces both spinal antinociception and CNS concentration of systemically administered morphine in rats. Brain Res 1991;555:251-258.

21. Messer M. Enzymatic cyclization of L-glutamine and L-glutaminyl peptides. Nature 1963;197:1299.

22. Zloković BV, Lipovac MN, Begley DJ, et al. Slow penetration of thyrotropin-releasing hormone across the blood-brain barrier of an in situ perfused guinea pig brain. J Neurochem 1988;51:252-257.

23. Rosa M, Arsequell G, Rougeot C, et al. Structure-activity relationship study of opiorphin, a human dual ectopeptidase inhbitor with antinociceptive properties. J Med Chem 2012;55:1181-1188.

24. Rougeot $\mathrm{C}$, inventor; Opiorphin peptide derivatives as potent inhibitors of enkephalin degrading ectopeptidases. World patent 124948. 2009. 